\title{
Effect of Micro-porosities on Fatigue Behavior in Aluminum Die Castings by 3D X-ray Tomography Inspection
}

\author{
Qian WAN, Haidong ZHAO* and Chun ZOU \\ School of Mechanical and Automotive Engineering, South China University of Technology, Guangzhou, 510641 China. \\ (Received on August 28, 2013; accepted on January 8, 2014)
}

\begin{abstract}
In this investigation, porosities in fatigue specimens obtained from practical ADC12 high pressure die castings were detected and reconstructed with high resolution X-ray computed tomography technology. Three dimensional (3D) characterizations of the porosities were analyzed. The high cycle fatigue tests were carried out at five stress amplitudes on seven groups of the specimens with different porosity contents. The Weibull analysis suggested less scatter of the fatigue life at larger stress condition. With the SEM observation on the fatigue fractured surfaces, the porosities initializing the fatigue cracks were identified. A pore-fatigue life prediction equation was deduced with the pore characteristics from the fracture surface and 3D X-ray tomography inspection. With 3D reconstruction of tomography data and FEA method, the simulation of the stress distribution around the actual 3D pores were carried out and analyzed further.
\end{abstract}

KEY WORDS: high pressure die casting; porosity; fatigue; three dimensional tomography; finite element analysis.

\section{Introduction}

High pressure die casting (HPDC) is the primary process to fabricate aluminum components for automotive as well as other industries. Due to the high injection velocity of molten metal in the process, entrapment of the cavity gas usually happens and results in porosities, which are detrimental to casting mechanical properties and act as fatigue cracks. ${ }^{1-4)}$ Researchers have contributed a lot of works to effect of porosities on casting tensile properties and fatigue performance. Weiler ${ }^{5)}$ and $\mathrm{Hu}^{6}$ studied relationship between internal porosity and fracture strength of die-cast magnesium alloys. In author's former research, ${ }^{7)}$ the influence of porosity size and fractions on the ADC12 die castings was investigated and the critical size and fraction were proposed for the qualified castings. Wang ${ }^{8)}$ used a two-parameter Weibull method to analyze fatigue life of A356 alloys with or without defects. $\mathrm{Lu}^{9)}$ studied the effect of porosity on fatigue crack initiation of die-cast AM60 alloy with experiment and simulation, and showed more stress concentration around the awkward star shaped pore than the idealized round pore. In these studies, the porosities measurement were performed based on the metallographic images of two-dimensional (2D) sections and the 2D artificial porosity geometry models rather than the actual spatial ones were used in the stress finite element analysis (FEA). Recently, development of

This article is one which was originally scheduled for publication in the special issue (Vol. 54, No. 2) on "Cutting Edge of Computer Simulation of Solidification, Casting and Refining" and instead was specially published in this regular issue.

* Corresponding author: E-mail: hdzhao@scut.edu.cn DOI: http://dx.doi.org/10.2355/isijinternational.54.511 high-resolution X-ray tomography has provided the possibility for study on 3D morphologies of casting pores in detail. $^{10)}$ Felberbaum and Rappaz ${ }^{11)}$ studied the micro-pores in $\mathrm{Al}-\mathrm{Cu}$ alloys with and without inoculants by using high resolution X-ray tomography and estimated the pore curvatures. They found that small distinct pores shown in 2D sections were, in fact, interconnected in spatial. This implies that $2 \mathrm{D}$ analysis of casting pores may overestimate pore numbers and underestimate pore shape complexity and sizes. Therefore, it is desirable to investigate relationship between $3 \mathrm{D}$ characterization of porosities and fatigue properties.

In this study, 3D characteristics of porosities in fatigue specimens from ADC12 HPDCs were investigated by using $\mathrm{X}$-ray tomography technology and then high cycle fatigue test was conducted. The effect of the porosities on the fatigue properties was analyzed and a fatigue life prediction model for ADC12 die castings was derived. With the actual geometry model from the X-ray tomography inspection, the stress concentration caused by the porosities was simulated with FEA method and discussed further.

\section{Experimental}

The specimens for the X-ray tomography scan and fatigue test were sectioned from a practical ADC12 HPDC. The casting is of $5842 \mathrm{~g}$ in weight and $480 \times 360 \times 70 \mathrm{~mm}$ in dimension. It was fabricated with a UBE $16500 \mathrm{kN}$ cold chamber die casting machine. During the die casting process, the melt pouring temperature was $680^{\circ} \mathrm{C}$, and the shot speeds were 0.1 to 0.8 and $4.0 \mathrm{~m} / \mathrm{s}$ during the slow and high injection periods, respectively. The intensification pressure was set to $65 \mathrm{MPa}$. The casting's actual compositions, as 


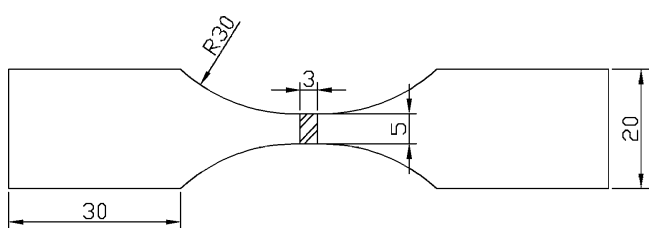

Fig. 1. Geometry and dimensions of fatigue specimens (Unit: $\mathrm{mm}$ ).

obtained from chemical analysis with LEEMANLABS Pulsar, are composed of $10.77 \mathrm{Si}, 1.87 \mathrm{Cu}, 0.78 \mathrm{Fe}, 0.78 \mathrm{Zn}$, $0.20 \mathrm{Mn}, 0.17 \mathrm{Mg}$, and balance $\mathrm{Al}$ in mass $\%$, which are satisfied with ADC12 alloy specification according to JIS standards. Total 40 specimens according to the ASTM standard, of which dimensions are shown in Fig. 1, were machined from the casting of average $4 \mathrm{~mm}$ wall thickness.

Before the fatigue test, porosities in the gauge length of all specimens were nondestructively detected with high resolution X-ray tomography. The detection was performed on a 3D X-ray tomography machine, which can provide a maximum energy of $225 \mathrm{kV}$. Radiographic images were acquired at spatial resolution of $5 \mu \mathrm{m}$ and reconstructed by VGStudio $\operatorname{Max}^{\circledR} 2.0$ software. Hence 3D characterization and distribution of pores in the specimens were obtained and analyzed.

According to the porosity fractions in the specimens, they were classified into 7 groups with the average porosity fractions of $0.91 \%, 0.71 \%, 0.56 \%, 0.48 \%, 0.43 \%, 0.31 \%$ and $0.15 \%$, respectively, and each group had at least 5 specimens. For each group, the high cycle fatigue tests had been carried out at five stress levels of 110, 130, 145, 160, and $190 \mathrm{MPa}$ with a servo-hydraulic INSTRON 8874 fatigue testing machine. In the test, sinusoidal wave form with a frequency of $30 \mathrm{~Hz}$ and stress ratio $(R)$ of 0.1 was used under the controlled temperature of $20^{\circ} \mathrm{C}$. The fractured surfaces of all specimens were observed with a scanning electron microscope (SEM) and the pores initiating fatigue cracks on the fractured surfaces were examined as well.

\section{Results and Discussion}

\subsection{D Characteristics of Porosities}

Figure 2 displays the porosities in four fatigue specimens. Due to the high injection velocity of molten metal in HPDC processes, turbulent filling flow often causes entrapment of the cavity gas and results in porosities in casting. ${ }^{7)}$ As a result, all the fatigue specimens have pores with different contents. The pores have different contrast than aluminum matrix in series images obtained by transmission Xray, and hence their 3D morphology in spatial are clearly visible after reconstruction. The analysis of the pore 3D characteristics showed that there existed three types of porosities, namely, gas, gas-shrinkage, and shrinkage, in the investigated castings as shown in Fig. 3. The gas pores in the die castings were with low volume and near round shape. The shape of gas-shrinkage pore was presented as gas pore with many convexes and long tails. Its volume was higher than that of the gas pore. The shrinkage pore was with low volume and very complex shape. Since high resolution 3D tomography techniques provided detailed morphology of each pore, it was easy to distinguish the different types of pores in the die castings. The details about the char- (a)

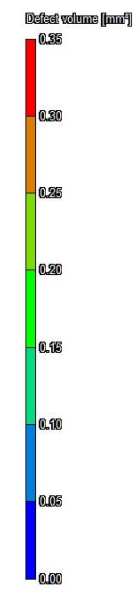

$\stackrel{2}{L}^{2} x$

(a) $1 \#-0.15 \%$

(c)

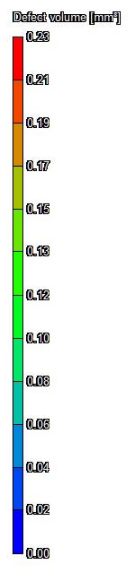

$\stackrel{2}{2} \times$

(c) $24 \#-0.55 \%$ (b)

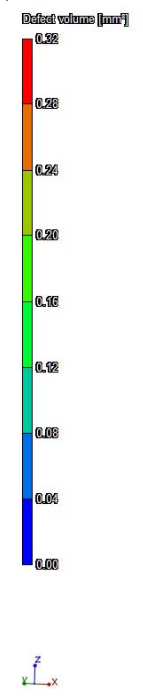

(b) $31 \#-0.35 \%$

(d)
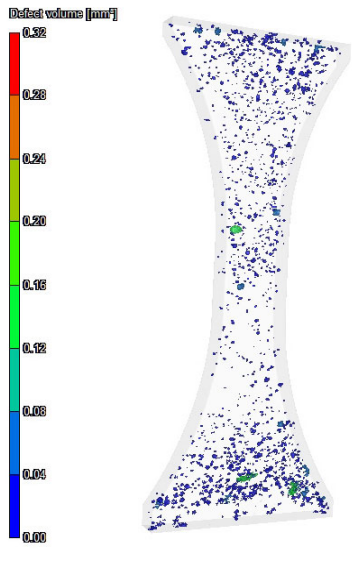

$I^{2} \cdot x$

(d) $32 \#-0.75 \%$

Fig. 2. 3D views of porosities distribution in fatigue specimens. (Online version in color.)

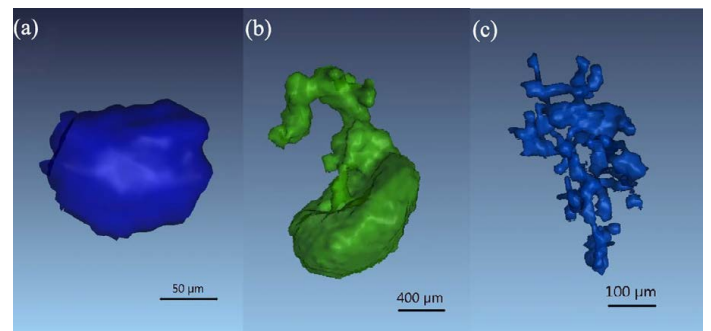

Fig. 3. Typical morphology of the detected (a) gas, (b) gas-shrinkage, and (c) shrinkage pores. (Online version in color.)

acteristics and formation of the three types of pores were presented in author's former work. ${ }^{12)}$

\subsection{Effect of Pores on Fatigue Properties}

The results of the stresses and numbers of cycles to failure in the fatigue test were plotted in Fig. 4 with logarithmic coordinates, and the linear regression was applied to the fatigue lives of the specimens in 7 groups classified by dif- 


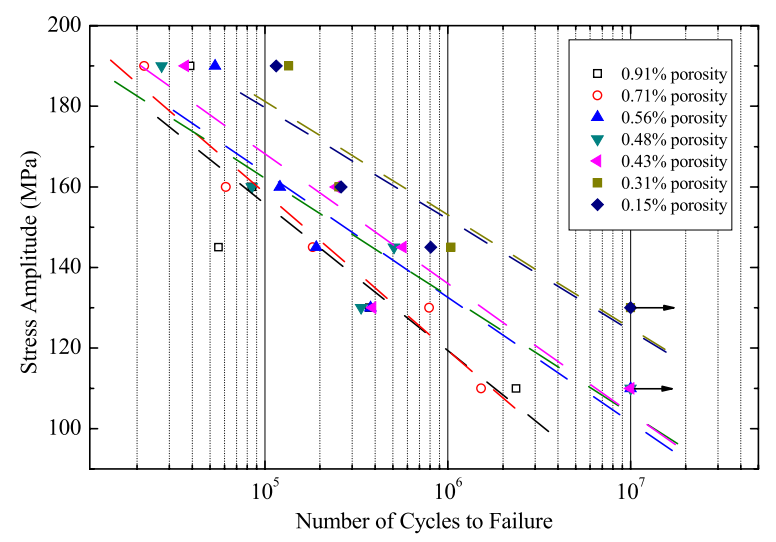

Fig. 4. Stress-fatigue life of specimens with different porosities. (Online version in color.)

ferent porosity contents. It was obvious that the fatigue lives decreased with the increase of porosities. It was found that for the $\mathrm{ADC} 12$ die casting with porosity fractions no more than $1 \%$, the scatter of fatigue life was less than one order of magnitude.

Statistical analysis method, especially Weibull distribution, was usually used to study scatter of fatigue lives for understanding fatigue performance at different conditions. ${ }^{8,13)}$ The 3-parameter Weibull distribution could be presented as ${ }^{14)}$

$$
F_{w}(N)=1-\exp \left[-\left(\frac{N-N_{0}}{N_{c}}\right)^{b}\right]
$$

where, $F_{w}(N)$ means the percent of all specimens which will failed at or below the given fatigue cycles; $N$ is the fatigue cycle of fracture specimen; $N_{c}$ is the critical fatigue cycle, which means at this fatigue cycle there were $63.2 \%$ of all fatigue specimens will failed; $N_{0}$ is the threshold value of fatigue life, and $b$ is the 3-parameter Weibull modulus (shape parameter), which means the scatter of the data. If $N_{0}$ equals to zero, Eq. (1) expresses the common 2-parameter Weibull distribution.

Equation (1) has been applied to the fatigue test results without the data at the $110 \mathrm{MPa}$ test due to only two specimens fractured at this stress load. The regression of the 3parameter Weibull distribution of fatigue cycles was performed on at 130 to 190 stress levels as shown in Fig. 5. It is believed that more data for Weibull analysis can improve regression accuracy. $\mathrm{Wang}^{8)}$ et al. used dozens of data in the analysis to study the effect of slip band, porosity and oxides on the fatigue of gravity die cast A356 alloys. Due to limitations of experiment, researchers sometimes had to take use of less data. Lee ${ }^{13)}$ et al. regressed the fatigue lives at 220 $\mathrm{MPa}$ of 7 samples of gravity die cast A356 alloys; EspinozaCuadra $^{15)}$ et al. used only 4 data of tensile strengths of the as-cast A319 alloys in Weibull analysis. In present Weibull analysis, the fatigue lives of 32 specimens at four stress levels were treated, and the fatigue lives of only 6 specimens at $130 \mathrm{MPa}$ were calculated because 2 specimens were not fractured at the stress. Table 1 lists all the estimated parameters in the regression as well as the number of fractured specimens, and they indicate that the Weibull modulus ( $b$ in Eq. (1)) at $190 \mathrm{MPa}$ and $160 \mathrm{MPa}$ stress conditions were higher than those of the $145 \mathrm{MPa}$ and $130 \mathrm{MPa}$, implying that fatigue lives of high pressure die cast ADC12 alloys at

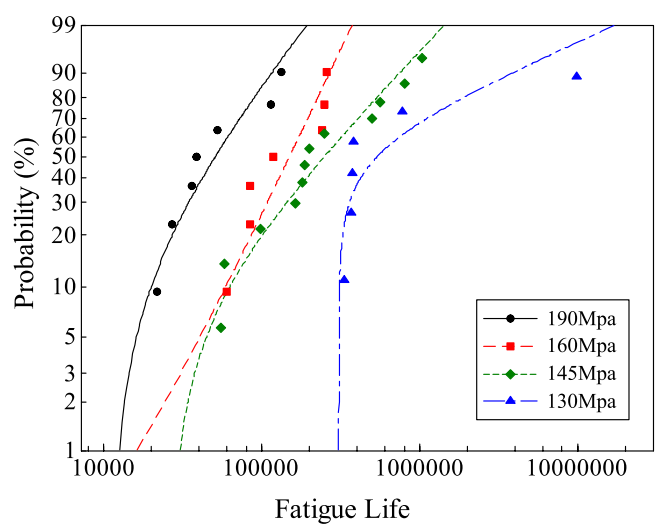

Fig. 5. 3-parameter Weibull fitting results of fatigue lives at different stress amplitudes. (Online version in color.)

Table 1. Estimated parameters of 3-parameter Weibull distribution of fatigue lives.

\begin{tabular}{cccccc}
\hline $\begin{array}{c}\text { Stress } \\
\text { Amplitude } \\
(\mathrm{MPa})\end{array}$ & $\begin{array}{c}\text { Shape } \\
\text { parameter, } \\
b\end{array}$ & $\begin{array}{c}\text { Scale } \\
\text { parameter, } \\
N_{c}\end{array}$ & $\begin{array}{c}\text { Threshold } \\
\text { value, } N_{0}\end{array}$ & Number & $\mathrm{A}^{2}$ \\
\hline 190 & 1.247 & 53729 & 11352 & 7 & 0.394 \\
160 & 2.126 & 185805 & -4860 & 7 & 0.684 \\
145 & 1.030 & 321512 & 27259 & 12 & 0.317 \\
130 & 0.4415 & 533935 & 311841 & 6 & 0.709 \\
\hline
\end{tabular}

$\mathrm{A}^{2}$ is the Anderson-Darling goodness-of-fit test statistic.

higher stress amplitudes show less scatter.

\subsection{Fatigue Life Prediction}

For searching the defects responsible for fatigue-crack initiation in the specimens, all of the fracture surfaces were observed and examined with SEM. It was found that fatigue cracks initiated from pores in more than $80 \%$ of the fractured specimens whereas only 2 pieces of specimens failure were originated from inclusions. Furthermore, it can be confirmed that gas pores were the dominated factor for fatigue failure except for gas-shrinkage pores near or at surface act as fatigue crack sources in few of the specimens, and all the pores responsible for initiation of fatigue cracks were over $100 \mu \mathrm{m}$. It should be noted that fatigue cracks could initiated from relative small pores but position near or at surface (Figs. 6(a) and 6(b)) as well as lager pores inside the specimens (Fig. 6(c)). This indicates that not only pore size but also pore location has significant effect on casting fatigue behavior. Perhaps the stress concentration caused by pores determines its play in fatigue test (to be present in next section). After determining the pore defect (for an example shown in Fig. 6(c)), the corresponding pore reconstructed in the 3D X-ray tomography inspection was searched and then the pore characteristics were established, an example of which is presented in Fig. 6(d).

The total fatigue life, $N_{f}$, consists of cycles in crack initiation and propagation periods, $N_{i}$ and $N_{p}$, respectively. Because of the porosity appearance in all specimens, the fatigue cracks could directly grow from the pores. Therefore the fatigue crack initiation period could be neglected and the fatigue life was mainly determined by the crack growth. The crack growth rate and fracture toughness of the material can be described by Paris law ${ }^{16}$ ) 


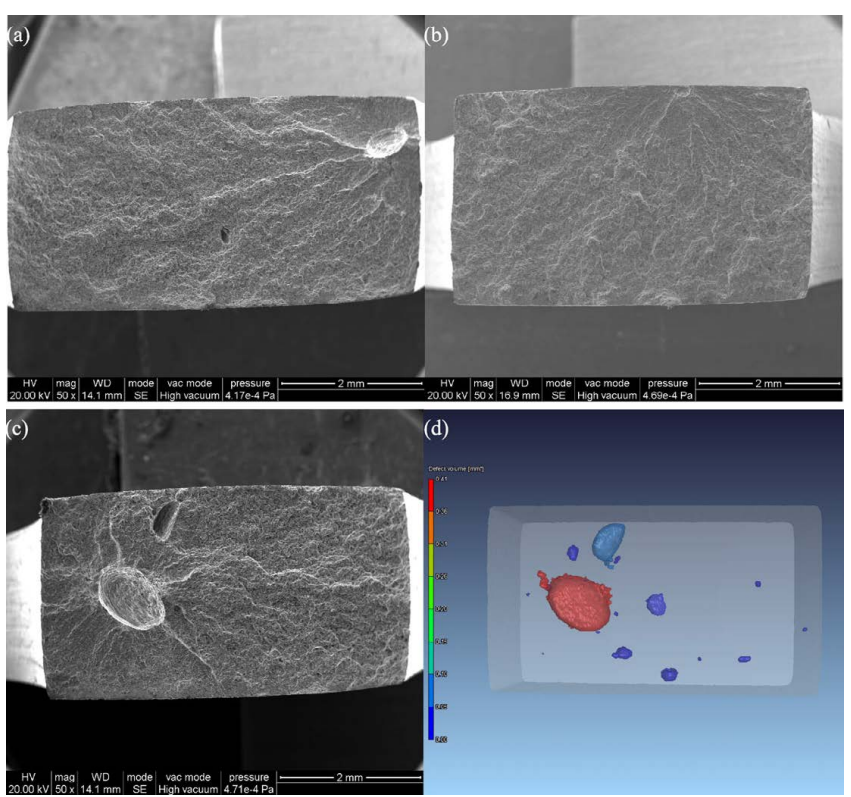

Fig. 6. (a) (b) and (c) Pore responsible for fatigue-crack initiation, and (d) 3D reconstructed morphology of pores in section (c). (Online version in color.)

$$
\frac{d a}{d N}=C\left(\Delta K_{e f f}\right)^{m}
$$

where, $a$ is crack size; $N$ is cycle number; $C$ and $m$ are coefficients responding to different alloys; $\Delta K_{\text {eff }}$ is the effective stress intensity factor range as below

$$
\begin{aligned}
& \Delta K_{\text {eff }}=K_{\text {max }}-K_{\text {opening }}=U_{R}(a) \Delta K \\
& \Delta K=Y(a) \Delta \sigma \sqrt{\pi a}
\end{aligned}
$$

where $U_{R}(a)$ is the crack closure factor related to the stress ratio $(R)$ and crack size $(a), Y(a)$ is the geometry factor and $\Delta \sigma$ is the applied stress range.

The crack size $(a)$ could be described approximately by $\sqrt{\text { area }}$ (square root of the defect area projected onto a plane perpendicular to applied stress), ${ }^{17)}$ and $Y(a)$ is 0.5 for pore inside while $Y(a)$ is 0.65 for pore near surface. ${ }^{18)}$ The porefatigue life model was deduced as follow

$$
\int_{a_{i}}^{a_{f}} \frac{\mathrm{d} a}{Y(a)^{m} U_{R}(a)^{m} \cdot(\pi a)^{m / 2}}=C \cdot(\Delta \sigma)^{m} \int_{N_{i}}^{N_{f}} \mathrm{~d} N
$$

Taking $N_{P}\left(=N_{f}-N_{i}\right)$ as the number of cycles to propagation to failure, Eq. (5) can be changed to

$$
\begin{aligned}
& a_{f}^{(2-m) / 2}-a_{i}^{(2-m) / 2} \\
& =\frac{2-m}{2} C Y\left(a_{i}\right)^{m} U_{R}\left(a_{i}\right)^{m} \pi^{\frac{m}{2}}(\Delta \sigma)^{m}\left(N_{f}-N_{i}\right)
\end{aligned}
$$

where $a_{i}$ and $a_{f}$ are initial crack size (consider as pore size in this study) and final crack size after failure. Because $a_{f}$ is much larger than $a_{i}$ and $m \geq 4,{ }^{19)}$ the term $a_{f}^{(2-m) / 2}$ in Eq. (6) is considered negligible and then Eq. (6) can be rewritten as

$$
a_{i}^{(2-m) / 2} N_{\mathrm{P}}^{-1}=\frac{m-2}{2} C Y\left(a_{i}\right)^{m} U_{R}\left(a_{i}\right)^{m} \pi^{\frac{m}{2}}(\Delta \sigma)^{m}
$$

Due to two variables of $a_{i}$ and $N_{P}$ to be solved, Eq. (7) can be simplified as

$$
a_{i} N_{\mathrm{P}}=B \cdot(\Delta \sigma)^{-m}
$$

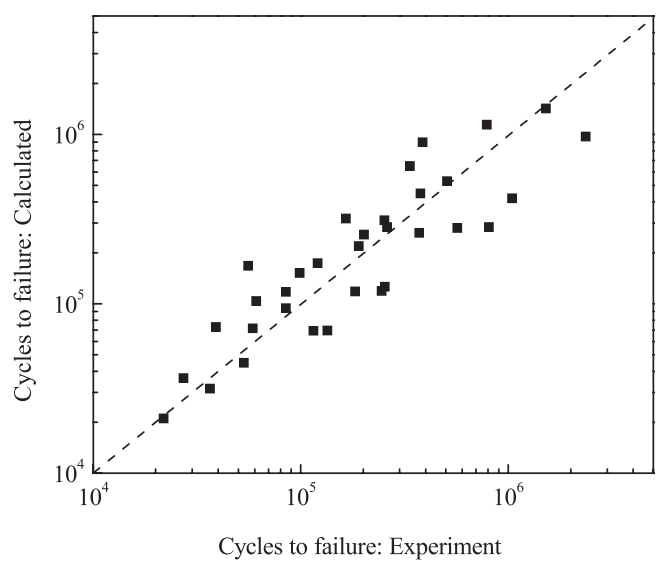

Fig. 7. Comparison of the experiment and calculation fatigue lives.

where $B$ is given by

$$
B=\left[\frac{m-2}{2} C Y\left(a_{i}\right)^{m} U_{R}\left(a_{i}\right)^{m} \pi^{m / 2}\right]^{-1}
$$

Considering the crack closure factor, $U_{R}\left(a_{i}\right)$, was chosen as 1 at $R=0.1,{ }^{19)}$ Eq. (8) could be transformed to the following lognormal format as,

$$
\lg \left(a_{i} N_{p}\right)=\lg B-\operatorname{m} \lg (\Delta \sigma)
$$

With the experimental stresses, fatigue lives and pore size from the fractured surfaces and X-ray tomography, the parameters $B$ and $m$ in Eq. (10) of the pore-fatigue life equation for the investigated casting was deduced by regression analysis. The regressed values of $B$ and $m$ are $6.01 e^{21}$ and 6.63 , respectively. Then the pore-fatigue life prediction expression can be given by

$$
a_{i} N_{p}=6.01 e^{21}(\Delta \sigma)^{-6.63}
$$

As above-mentioned, the fatigue cracks could directly grow from the pores and the fatigue life was mainly determined by the crack propagation. Consequently, Eq. (11) can describe the whole fatigue life. $a_{i}$ is considered as the dimension of the fatigue-initiating pore which could be measured on the fractured surface, and it is clear that $\Delta \sigma$ represents the applied stress range in the fatigue experiment. Therefore, the fatigue cycles $\left(N_{p}\right)$ could be calculated by using Eq. (11). Figure 7 compared two results of the fatigue lives of the experiment and calculation by Eq. (11). The good agreement in two results indicated that Eq. (11) may be usage for prediction of fatigue life of ADC12 die castings.

\subsection{D Finite Element Analysis of Stress Around Pores}

Finite element modeling of stress concentration caused by pores in castings can provide important information to understand effect of different pore characteristics including size, shape, and location, on casting failure. In this study, the methods of 3D reconstruction of tomography data and FEA were applied to simulate the stress around the actual 3D pores.

To carry out the FEA, the 3D finite element meshes considering the pores should be built first. The aluminum matrix and pore were serially labeled in the binary image to determine their interfaces, and then the aluminum boundary was meshed by triangular facets using Mimics ${ }^{\circledR}$ software. Hence by reconstructing there serial section meshes, the $3 \mathrm{D}$ geometry model with the pores inside could be established 


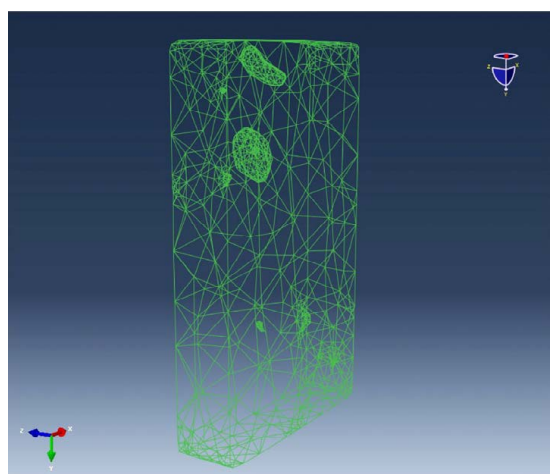

Fig. 8. Finite element meshes considering inside actual pores. (Online version in color.)

and then was inputted into FEA software ABAQUS ${ }^{\circledR}$ directly. During the input, the mesh type was transferred from triangle to 4-node tetrahedron with linear interpolation. Figure 8 shows finite element meshes of a part of a specimen with transparent display model to show the inside pores which were responsible for the specimen fatigue failure initiation according to SEM examination. It should be noticed that the grids should be very carefully meshed to ensure their quality, which affected next stress analysis calculation diffusion.

In the FEA setup, the material properties of the investigated ADC12 alloy were assigned to the model of elastic law; the alloy density was set to $2700 \mathrm{Kg} / \mathrm{m}^{3}$; the elastic module and Poisson ratio were $70 \mathrm{GPa}$ and 0.3 , respectively. As for boundary load along the tensile direction, the fatigue test pressure was set to be applied on one boundary face and the opposite face was set as clamped.

After the finite element analysis with ABAQUS, the stress distribution in the specimen under the fatigue load can be given. Figure 9(a) shows the Von Mises stress distribution around the pores in fractured surface of a specimen. It was obvious that the pores resulted in serious stress concentration. Although the pore 1 in Fig. 9(a) was smaller than the pore 2, however the maximum stress of $307.9 \mathrm{MPa}$ was found around the pore 1. Fig. 9(b) shows the specimen fracture surface morphology, demonstrating that the pore near the boundary acted as the fatigue crack nucleation site. It was indicated that the FEA results were agreement with the experiment, and that pores near casting surfaces could cause more stress concentration and be more detrimental to casting performance.

Since the reconstruction, finite element mesh generation, and stress FEA were very computation and time consuming, the FEA work have been performed to several specimens only. But the methods and procedures carried out in this research provided a new approach to assess effect of pores with actual $3 \mathrm{D}$ characteristics on casting properties.

\section{Conclusions}

In this investigation, the pore characteristics in the fatigue specimens from ADC12 high pressure die castings were inspected by $3 \mathrm{D}$ X-ray computed tomography and their effect on the fatigue lives were analyzed. By using 3D reconstruction of tomography data and FEA method, the stress distribution around the inside actual 3D pores were simulated. The research leads to the following points.

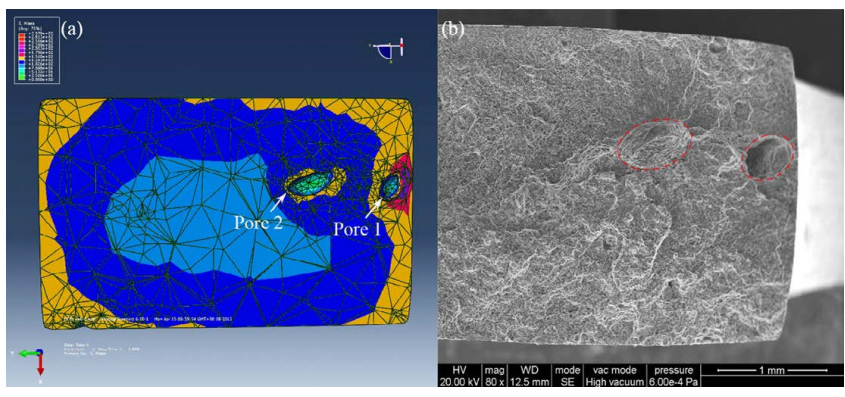

Fig. 9. (a) Stress distribution around pores and (b) the corresponding fracture surface. (Online version in color.)

(1) the fatigue lives decreased with the increase of porosities. It was found that for the ADC12 die casting with porosity fractions no more than $1 \%$, the scatter of fatigue life was less than one order of magnitude.

(2) the Weibull analysis indicated that at higher stress conditions, the fatigue lives of the ADC12 high pressure die castings showed less scatter.

(3) based on the Paris law, the pore-fatigue life prediction equation was deduced with the pore characteristics from the fracture surface and 3D X-ray tomography inspection. The predicted fatigue lives exhibited well agreement with the experiment results.

(4) with consideration of the inside actual pores, the stress distribution by the 3D FEA were in agreement with the experimental fracture, and pores near casting surfaces could cause more stress concentration and be more detrimental to casting performance.

\section{Acknowledgements}

This work was supported by the project National Natural Science Foundation of China (51375171, U1034001) and the National 863 Project (2013AA031201).

\section{REFERENCE}

1) R. A. Hardin and C. Beckermann: Int. Conf. of Modelling of Casting and Advanced Solidification Processes (MCWASP XIII), ed. by A. Ludwig, et al., IOP Publishing, London, (2012), 012069.

2) J. Linder, A. Arvidsson and J. Kron: Fatigue Fract. Eng. Mater. Struct., 29 (2006), 357.

3) Y. X. Gao, J. Z. Yi, P. D. Lee and T. C. Lindley: Fatigue Fract. Eng. Mater. Struct., 27 (2004), 559.

4) N. Vanderesse, J. Y. Buffiere, E. Maire and A. Chabod: Conf. Proc. of the Society for Experimental Mechanics Series, Vol. 5, ed. by T. Proulx, Springer Science+Business Media, New York, (2011), 55.

5) J. P. Weiler, J. T. Wood, R. J. Klassen, E. Maire, R. Berkmortel and G. Wang: Mater. Sci. Eng. A, 395 (2005), 315.

6) H. Hu, M. Zhou, Z. Sun and N. Li: J. Mater. Process. Technol., 201 (2008), 364

7) H. D. Zhao, F. Wang, Y. Y. Li and W. Xia: J. Mater. Process. Technol., 209 (2009), 4537.

8) Q. G. Wang, D. Apelian and D. A. Lados: J. Light Met., 1 (2001), 73.

9) Y. Lu, F. Taheri, M. A. Gharghouri and H. P. Han: J. Alloy. Compd., 470 (2009), 202.

10) G. Nicoletto, R. Konečná and S. Fintova: Int. J. Fatigue, 41 (2012), 39.

11) M. Felberbaum and M. Rappaz: Acta Mater., 59 (2011), 6849.

12) Q. Wan, H. D. Zhao and C. Zou: Acta Metall. Sin., 49 (2013), 284.

13) J. Z. Yi, Y. X. Gao, P. D. Lee, H. M. Flower and T. C. Lindley: Metall. Mater. Trans. A, 34 (2003), 1879.

14) J. Campbell: Complete Casting Handbook, Metal Casting Processes, Metallurgy, Techniques and Design, Butterworth-Heinemann, Oxford, (2011), 499.

15) J. Espinoza-Cuadra, G. García-García and H. Mancha-Molinar: Mater. Design, 28 (2007), 1038.

16) E. Wolf: Eng. Fract. Mech., 2 (1970), 37.

17) Y. Murakami and S. Beretta: Extremes, 2 (1999), 123.

18) Y. Murakami: Int. J. Fatigue, 41 (2012), 2.

19) M. J. Couper, A. E. Neeson and J. R. Griffiths: Fatigue Fract. Eng. Mater. Struct., 13 (1990), 213. 